
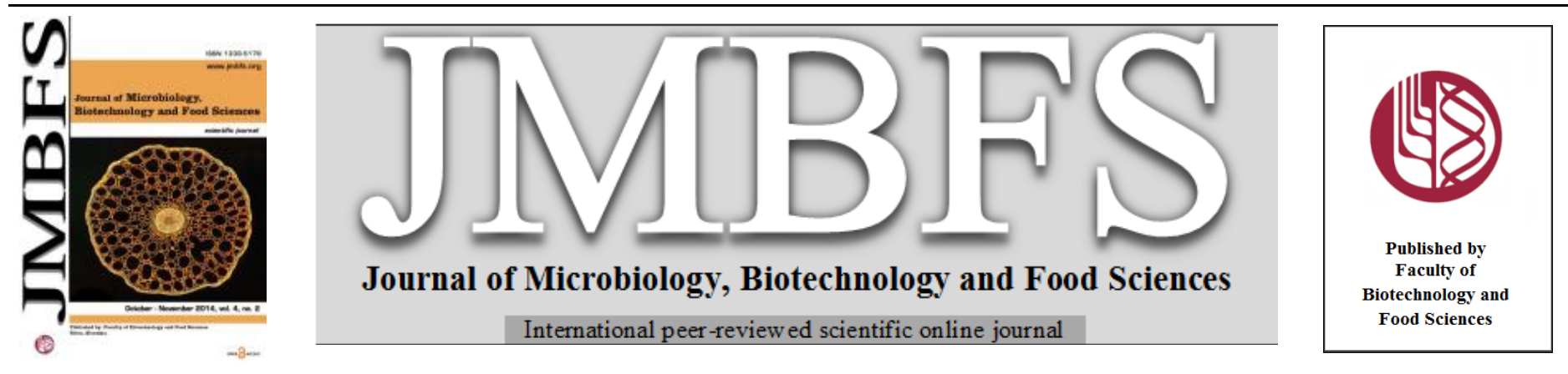

\title{
GROWTH AND MASS SPECTROMETRY PROFILE OF ALTERNARIA ALTERNATA PIGMENT GROWN IN MAIZE GRAIN EXTRACT
}

\author{
Sagarika Devi ${ }^{\prime}{ }^{1}$, Hemanth AK. Kumar ${ }^{2}$, Geetha Ramachandran ${ }^{2}$, Chandrasekarenthiran Subramanian ${ }^{1}$, Perumal Karuppan $^{l}$ \\ Address(es): Sagarika Devi \\ ${ }^{1}$ Shri AMM Murugappa Chettiar Research Centre, Taramani, Chennai-600113, India, Tel: +9144- 22430937, +919677225681. \\ ${ }^{2}$ Department of Biochemistry \& Clinical pharmacology, National Institute for Research in Tuberculosis, No.1, Sathiyamoorthy Road, Chetput, Chennai -600031 , \\ India. Tel: +9144- 28369657, +919444076305.
}

*Corresponding author: sagarikadevi@mcrc.murugappa.org

doi: $10.15414 / j m b f s .2014 .4 .2 .179-184$

ARTICLE INFO

Received 18. 6. 2014

Revised 12. 9. 2014

Accepted 22. 9. 2014

Published 1. 10. 2014

$\overline{\frac{\text { Regular article }}{\text { OPEN }{ }_{\text {ACCESS }}}}$

\begin{abstract}
Alternaria species are common saprophytes found in a variety of habitats as ubiquitous agents of decay. Alternaria spp. produces about sixty different secondary metabolites. In the present investigation, growth and production of pigment from Alternaria alternata was studied in maize grain extract at $\mathrm{pH}$ 4-9. The reddish brown pigment was extracted, estimated and partially purified by fractionation. Through mass spectrometry, major constituents of pigment from Alternaria alternata such as Tenuazoic acid (m/z 198), Stemphyperylenol (m/z 253), Alterperylenol (m/z 351), Alternariol (m/z 259.200), Altenuene (m/z 292), Alternarienoic acid (m/z 279.35) and Alternariol 5 methyl ether (m/z 273.20) were identified. The bio-prospecting of these secondary metabolites in industrial applications is also discussed.
\end{abstract}

Keywords: Alternaria alternata, fungal pigment, mass spectrometry, secondary metabolites

\section{INTRODUCTION}

Micro-organisms are potential biocatalysts in the biotransformation process of natural products and are sources of several novel bioactive substances (Pimentel et al., 2011). Similar to plants, there is a long history of the utilisation of fungi by mankind as remedies and in everyday life. Nearly 3000 years ago the Mayans used fungi to treat intestinal ailments (Strobel et al., 2004). Without deeper knowledge about the mode of action, the transformation by fungi, they have been used for food production since Neolithic times. It has been well known that apart from a variety of plants and animals, microorganisms also produce pigments (Lauro, 1991; Masahiro et al., 1994; Kim et al., 1995; 1998a, b). The pigments produced by many fungi have been used as a natural food colourant for fish, bean curd and wine. The natural pigments produced by Monascus spp. have been looked upon with favour as safe natural colour and a replacement for synthetic pigments.In 1974, the American Miriam C. Rice published the first book concerning dyeing with fungi and since then, the custom has spread all over the world (Aittomaki et al., 2000). An orange pigment from the fungi Ganoderma applanatum, Coriolus versicolor and Amanita muscaria was extracted from the basidiocarp and applied on silk and cotton fabrics (Perumal et al., 2004). In this context, it is of great relevance that microbes are producers of large number of bioactive compounds (Zhang et al., 2006) that have evidence of diverse application in agriculture, medicine and other industries (Strobel, 2002). Therefore the understanding and detailed study on the production of these fungal pigments should thus be encouraged to provide ample solutions to the increasing global concerns of a better and safe environment. Alternaria spp. are widely distributed in soil and on aerial plant surfaces (Ozcelik and Ozcelik, 1990). In addition to causing damage to vegetables, fruits and grains, Alternaria sp. produces several secondary metabolites. Metabolites of Alternaria alternata (Fries) Keissler (A. tenuis Auct.) were first isolated and characterized from 4 to 5 week cultures grown on Czapek-Dox liquid medium (Raistrick et al., 1953). The growth and production of secondary metabolites from micro organisms is predominantly dependent on the composition of growth medium and culture condition (Bills, 1995). This makes the study of various types of growth medium and condition imperative to investigate and generate a broad range of secondary metabolite production in microbes (Larsen et al., 2005). Alternaria sp. grows over a wide range of $\mathrm{pH}$, temperature and simple sugars. However the combined influence of these factors on biomass and pigment production has not been widely studied. In this study, we utilized cost effective maize grain extract (MGE) as culture medium to estimate the mycelial growth and production of pigment from A.alternata under the influence of $\mathrm{pH} 4-9$. Also we documented the secondary metabolite constituents in the reddish brown pigment of A.alternata through mass spectrometry (LCMS).

\section{MATERIAL AND METHODS}

\section{General}

For MS analysis, SHIMADZU LCMS 2010 consisting of gradient Ultra-Fast Liquid Chromatography (UFLC 20AD) pumps, SIL-HTc auto sampler, photo diode array detector SPD-M20A, coupled to a 2010EV mass spectrometer with ESI probe was used. LC Column dimensions: ODS C18 column (Phenomenex, $50 \mathrm{~mm} \times 5 \mu \mathrm{m} \times 2.1 \mathrm{~mm}$ ID). Column chromatography was carried out in a glass column $(32 \mathrm{~cm} \times 1.5 \mathrm{~cm})$ packed with silica gel $(240-400 \mathrm{mesh})$. All UV-Visible spectra data of collected fractions were recorded using Varian Cary 50 spectrophotometer at scan mode of $200-800 \mathrm{~nm}$.

\section{Alternaria culture conditions}

A. alternata, MTCC 2724 strain was obtained from Microbial Type Culture collection and Gene Bank (MTCC), IMTECH, Chandigarh, India. The culture was revived on sterile Potato Dextrose Agar (HIMEDIA, India) medium, incubated at $28^{\circ} \mathrm{C}$ and the $21 \mathrm{st}$ day mycelial culture served as inoculum for biomass and pigment production studies. Erlenmeyer flasks containing $50 \mathrm{~mL}$ maize grain broth (40g maize flour dissolved per litre deionized water) was taken individually as substrate and the $\mathrm{pH}$ value was adjusted to $4,5,6,7,8$ and 9 using $1 \mathrm{M} \mathrm{HCl}$ or $1 \mathrm{M} \mathrm{NaOH}$. The flasks containing medium were autoclaved at $121^{\circ} \mathrm{C}$ for $15 \mathrm{~min}$. The flasks were inoculated with $6 \mathrm{~mm}$ mycelial culture discs of the 21 day old A. alternata and incubated at $28^{\circ} \mathrm{C} \pm 2^{\circ} \mathrm{C}$ as stationary cultures. At every three days interval the flasks containing A. alternata were withdrawn and the mycelial mat was collected by filtration using filter paper. The harvested mycelial mat was air dried at $40{ }^{\circ} \mathrm{C}$ for $24 \mathrm{hrs}$. The obtained dry mycelia were extracted and estimated for pigment content following the method as described by Gadd (1982). Standard Melanin pigment obtained from Sigma Aldrich served as standard for quantification of pigment. All experiments were maintained in triplicates and the data was analyzed statistically. 


\section{Pigment estimation and purification}

Dry mycelium $(2 \mathrm{~g})$ was pre weighed, soaked in $10 \mathrm{~mL}$ of Methanol and well ground using a mortar and pestle. The mixture was allowed to stand overnight and then taken for extraction in soxhlet apparatus with $110 \mathrm{~mL}$ methanol. The extraction was continued for $10 \mathrm{hrs}$ with 20 intermittent cycles lasting $30 \mathrm{~min}$ each to obtain a deep reddish brown pigment (Chandrasekarenthiran, 2010 and Sumathi, 2008). The whole vacuum dried crude pigment extract was introduced in column chromatography setup with solvent system of n-hexane (100\%), Chloroform: Methanol (C: M) at 9:1, 8:2, 7:3, 5:5, 4:6, 3:7, 2:8, 1:9 followed by Methanol $(100 \%)$ and Water $(100 \%)$. The flow rate was maintained at $1 \mathrm{~mL} / \mathrm{min}$, and $2 \mathrm{~mL}$ of each fraction was collected in separate vials. The eluted fractions were determined at their respective absorbance maxima ( $\lambda$ max) in UV-Visible Spectrophotometer. Three coloured fractions namely 4, 13 and 16 were then submitted for LC-MS analysis.

\section{LC-MS Analysis}

The mobile phase A consisted of $0.1 \%$ Formic acid (v/v) in water $(\mathrm{H} 2 \mathrm{O})$, and the mobile phase B consisted of Methanol (MeOH) and $0.1 \%$ Formic acid (v/v). The following linear gradient used was; Solvent B - 0.01 min-10\%; Solvent B - 15 min $-100 \%$; Solvent B - 25 min-100\%. The samples were dissolved with $100 \%$ $\mathrm{MeOH}$ and $5 \mu \mathrm{l}$ sample was injected into the UFLC system and data were acquired and processed in Shimadzu LabSolution V3. The processed mass spectra were matched with compounds reported in previous literatures and searched through Pubchem compound database and NIST similarity search.

\section{NMR Mixture analysis of eluted fractions}

Mixture analysis of the eluted fractions was carried out using proton NMR (500 $\mathrm{MHz}$ Bruker Avance III NMR) to confirm the presence of mass spectrometric based identified compounds viz., Altenuene, Alternarienoic acid, AlternariolMonoethyl Ether, Alternariol, Alterperylenol, Stemphyperylenol, Tenuazoic Acid. The eluted fractions 4, 13 and 16 were redissolved in deuterated chloroform and analysed for ppm shifts. The recorded ppm shifts were matched with existing literature of fungal pigments and the components were identified using TopSpin software.

\section{RESULTS AND DISCUSSION}

We observed the maximum mycelial growth $(7.59 \pm 0.02 \mathrm{~g} / \mathrm{L})$ at $\mathrm{pH} 5$ on 9 th day of culture grown in Maize grain broth without supplementation of any other additional carbon or nitrogen sources. However, maximum pigment production of $14.3 \pm 0.86 \mathrm{mg} / \mathrm{g}$ dry mycelium was recorded in MGE at $\mathrm{pH} 6$ on 9 th day. Acidic $\mathrm{pH}$ supported better growth while at $\mathrm{pH} 7$ and with increase in alkalinity there was a decline in the fresh and dry mycelial growth.Low pH (4- 4.5) is reported ideal for the growth of A. alternata, while the minimum growth was observed in $\mathrm{pH}$ 9, irrespective of isolates (Ramjegathesh and Ebenezar, 2012). The pigment production also declined after 15 days of mycelial growth. No mycelial growth and pigment was recorded at $\mathrm{pH}$ 9.The dry mycelial growth and production of pigment from A. alternata grown on MGE at various $\mathrm{pH}$ is furnished in Table 1. Natural raw materials and by-products of industry (sugar cane molasses, corn steep liquor, cheese whey) have wide use as culture media in fermentation processes because of their low cost since the medium components can represent from 38 to $73 \%$ of the total production cost. Several studies have also been reported about the influence of culture media on metabolite production of Alternaria (Misaghi et al., 1977). The interacting effects of time, temperature, $\mathrm{pH}$ and simple sugars on biomass and mycotoxin production is reported in three Alternaria sp. where $25^{\circ} \mathrm{C}$ at $\mathrm{pH} 8$ is reported suitable for biomass production with enhanced toxin production at $15{ }^{\circ} \mathrm{C}$ (Ozcelik and Ozcelik, 1990). Alternaria citri and A. tenuis grew over a temperature range of 15 to $35^{\circ} \mathrm{C}$, and were able to grow at a pH range of 2.7 to 8.0 , the optimum being at 5.4 (Hasija, 1970) Maximum pigment production at $28^{\circ} \mathrm{C}$ at a standard time period of three weeks was also studied (Sharma et al., 2012). The maximum production of pigments was obtained when cultures were grown on potato dextrose agar (PDA) with $20 \%$ dextrose, an initial $\mathrm{pH}$ of 4.5 at $25-30^{\circ} \mathrm{C}$ under continuous darkness or diurnal light, and without wrapping the culture plates (Shabana et al., 2001).

The crude pigment extract $(0.310 \mathrm{~g})$ was purified using silica column chromatography. A total of 28 fractions were fractionated. The fraction no. $1 \& 2$ eluted with $\mathrm{n}$-hexane and fraction 3 eluted with Chloroform- Methanol at 9:1 were observed to be colourless at the retention time of $9.5 \mathrm{~min}$. At the same solvent gradient, a red fraction (4th fraction) eluted using Chloroform and Methanol partition of 9:1 was observed to have maximum absorption at the wavelength of 205, 207, 364 and $371 \mathrm{~nm}$ at the retention time of 13.5 . At 23.50 minutes, a brown fraction (8th fraction) eluted using Chloroform and Methanol partition of 8:2 was observed to have maximum absorption at 203 and $208 \mathrm{~nm}$. Similarly a violet fraction (Fraction 13 at retention time of $53.0 \mathrm{~min}$ ) and a brown fraction (Fraction 16 at retention time of 74.00) were collected using partition of Chloroform and Methanol at 7:3 and 5:5 ratios having maximum absorption at
$209,217,220 \mathrm{~nm}$ and $203 \mathrm{~nm}$ respectively. The UV-Visible spectra of fragments eluted from each solvent have been summarized in Figure 1.

Table 1 Influence of $\mathrm{pH}$ on mycelial growth ( $\mathrm{g} / \mathrm{litre}$ medium) and pigment (mg/gram biomass) of Alternaria alternata in Maize Grain Extract medium (MGE)

\begin{tabular}{|c|c|c|c|c|c|c|c|}
\hline \multirow{8}{*}{ 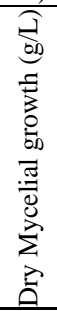 } & $\begin{array}{l}\text { Days of } \\
\text { Culture }\end{array}$ & $\mathrm{pH} 4$ & $\mathrm{pH} 5$ & $\mathrm{pH} 6$ & $\mathrm{pH} 7$ & $\mathrm{pH} 8$ & $\mathrm{pH} 9$ \\
\hline & 3 & $0.19 \pm 0.01$ & $1.24 \pm 0.04$ & $0.54 \pm 0.02$ & $0.36 \pm 0.01$ & $0.34 \pm 0.01$ & $0 \pm 0$ \\
\hline & 6 & $1.32 \pm 0.02$ & $3.78 \pm 0.01$ & $3.30 \pm 0.03$ & $1.70 \pm 0.04$ & $2.06 \pm 0.03$ & $0 \pm 0$ \\
\hline & 9 & $1.62 \pm 0.01$ & $7.59 \pm 0.02$ & $2.61 \pm 0.04$ & $2.04 \pm 0.02$ & $2.14 \pm 0.02$ & $0 \pm 0$ \\
\hline & 12 & $1.86 \pm 0.06$ & $3.29 \pm 0.01$ & $2.20 \pm 0.01$ & $2.01 \pm 0.01$ & $2.66 \pm 0.04$ & $0 \pm 0$ \\
\hline & 15 & $1.13 \pm 0.01$ & $2.46 \pm 0.02$ & $1.82 \pm 0.00$ & $1.56 \pm 0.02$ & $1.98 . \pm 0.02$ & $0 \pm 0$ \\
\hline & 18 & $0.65 \pm 0.01$ & $2.29 \pm 0.04$ & $1.31 \pm 0.01$ & $1.33 \pm 0.00$ & $1.17 \pm 0.02$ & $0 \pm 0$ \\
\hline & 21 & $0.45 \pm 0.01$ & $1.10 \pm 0.03$ & $0.77 \pm 0.04$ & $0.41 \pm 0.00$ & $0.82 \pm 0.02$ & $0 \pm 0$ \\
\hline \multirow{7}{*}{ 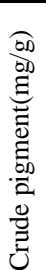 } & 3 & $1.26 \pm 0.06$ & $5.26 \pm 0.06$ & $\overline{0.60 \pm 0}$ & $\overline{0.80 \pm 0}$ & $2.53 \pm 0.06$ & $\overline{0 \pm 0}$ \\
\hline & 6 & $1.66 \pm 0.06$ & $6.46 \pm 0.06$ & $1.66 \pm 0.06$ & $4.20 \pm 0.23$ & $4.60 \pm 0$ & $0 \pm 0$ \\
\hline & 9 & $12.40 \pm 0.11$ & $7.33 \pm 0.13$ & $14.33 \pm 0.86$ & $4.46 \pm 0.06$ & $4.60 \pm 0$ & $0 \pm 0$ \\
\hline & 12 & $11.33 \pm 0.06$ & $10.86 \pm 0.06$ & $13.00 \pm 0$ & $12.46 \pm 0.06$ & $3.2 \pm 0$ & $0 \pm 0$ \\
\hline & 15 & $9.80 \pm 0$ & $6.00 \pm 0$ & $10.80 \pm 0$ & $3.30 \pm 0.06$ & $1.80 \pm 0$ & $0 \pm 0$ \\
\hline & 18 & $5.46 \pm 0.06$ & $2.26 \pm 0.06$ & $4.66 \pm 0.06$ & $2.26 \pm 0.06$ & $0.40 \pm 0$ & $0 \pm 0$ \\
\hline & 21 & $\overline{0.60 \pm 0}$ & $2.40 \pm 0$ & $4.80 \pm 0$ & $1.73 \pm 0.06$ & $\overline{0.20 \pm 0}$ & $0 \pm 0$ \\
\hline
\end{tabular}

12

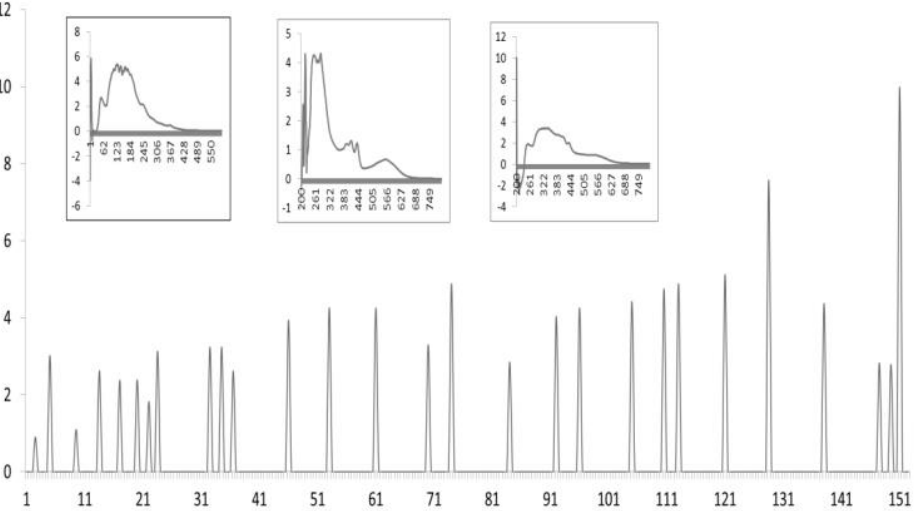

$\begin{array}{rrrrrrrrrrrrrrrr}1 & 11 & 21 & 31 & 41 & 51 & 61 & 71 & 81 & 91 & 101 & 111 & 121 & 131 & 141 & 151\end{array}$ solvent gradient of Hexane, Chloroform: Methanol (9:1, 8:2, 7:3, 5:5, 4:6, 3:7, $2: 8,1)$, Methanol, Water. Insets (a), (b) and (c) depicts UV-Visible scan of fractions 4,13 and 16 .

The LC chromatograms of the crude reddish brown pigment and eluted fractions i.e. $4,13 \& 16$ showed the presence of different metabolites of A. alternata. The compounds identified in fraction 4, 13 and 16 through previous literatures match have been summarized in Figure 2. The mass spectra of identified metabolites have been furnished in supplementary figures S1-S7.<smiles>COc1cc(O)c2c(c1)C1=CC(O)C(O)CC1(C)OC(=O)C2=O</smiles>

(a)<smiles>CC12CC(O)C(O)C=C1c1cc(O)cc(O)c1C(=O)O2</smiles>

(d)<smiles>COc1cc(O)c(C(=O)O)c(C2=C(C)C=C(O)C2=O)c1</smiles>

(b)<smiles>CC[C@H](C)[C@H]1NC(=O)C(C(C)=O)=C1O</smiles>

(e)<smiles>Cc1cc(O)cc2oc(=O)c3c(O)cc(O)cc3c12</smiles>

(c)

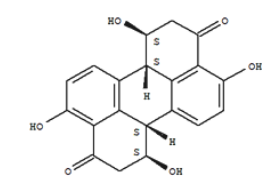

(g)

Figure 2 Identified compounds in Fraction 4, 13 and 16 [17] [19] (a) Alternariol, (b) Altenuene, (c) Alternarienoic acid, (d) Alternariol 5 methyl ether (e) Tenuazoic acid (f) Alterperylenol (g) Stemphyperylenol. 
In the crude methanol extract a total of 25 components were observed out of which 5 compounds were identified through previous literatures. The rest of the 17 mass spectra were searched through similarity search in the NIST Library, of which three were identified. Alternarienonic acid, was isolated with $\mathrm{m} / \mathrm{z} 279$ at the retention time of 12.171 with characteristic UV absorbance maxima at 231 and $291 \mathrm{~nm}$ (supplementary figure S1). At a retention time of $12.518 \mathrm{~min}$, Peak No 9, Tenuazoic acid was identified with $\mathrm{m} / \mathrm{z} 198$ and absorbance maxima at 229 and $288 \mathrm{~nm}$ (supplementary figure S2). At m/z 253 and retention time 14.932 min, Peak No13 was identified as Stemphyperylenol with absorbance maxima at 231, 263, 300 (supplementary figure S3). Peak No 25 was identified as Alterperylenol with RT: $21.443 \mathrm{~min}$, absorbance maxima $256 \mathrm{~nm}$ and m/z 351 (supplementary figure S4). Other unknown masses were searched with NIST database, in which peak No 3 was identified as Glufosinate $\left(\mathrm{C}_{15} \mathrm{H}_{12} \mathrm{NO}_{4} \mathrm{P}\right)$ with $\mathrm{m} / \mathrm{z} 181$, peak No 8 was identified as 8-Linoleolyl-benzoylhypaconine $\left(\mathrm{C}_{49} \mathrm{H}_{73} \mathrm{NO}_{10}\right.$ with $\mathrm{m} / \mathrm{z} 835$ and peak No 21 was identified as 18-(6-Hydroxypurin-9-yl)-benzo-18-crown-6 $\left(\mathrm{C}_{21} \mathrm{H}_{26} \mathrm{~N}_{4} \mathrm{O}_{7}\right)$ with $\mathrm{m} / \mathrm{z}$ ratio of 446 . The red fraction eluted with $\mathrm{C}$ : $\mathrm{M}: 9: 1$, showed 20 peaks out of which 4 were identified. Alternariol (Peak No 7) was identified at m/z [M+] 259.200 at RT 10.170 and absorbance maxima $255 \mathrm{~nm}$ (supplementary figure S5). Peak no 8 was identified as Altenuene at RT 10.170, m/z [M+] 292 and absorbance maxima 245, $312 \mathrm{~nm}$ (supplementary figure S5). Alternarienoic acid (Peak No 12) was identified at RT 14.054 and $\mathrm{m} / \mathrm{z}[\mathrm{M}+] 279.35$ revealing absorbance maxima 250, $277 \mathrm{~nm}$. At RT 12.009 and $\mathrm{m} / \mathrm{z}[\mathrm{M}+]$ 273.20, Alternariol 5 methyl ether (Peak No 9) was identified with absorbance maxima $338 \mathrm{~nm}$ (supplementary figure S7).

Table 2 LC/MS chromatograms of compounds identified in the reddish brown pigment of A.alternata

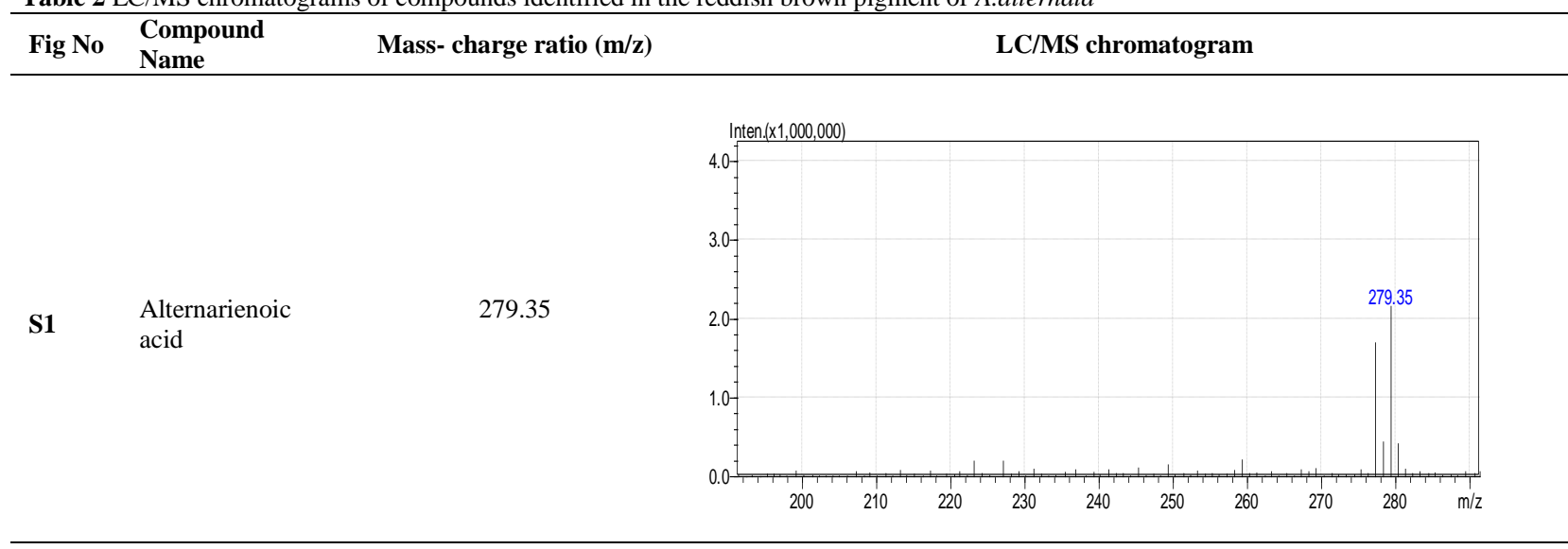
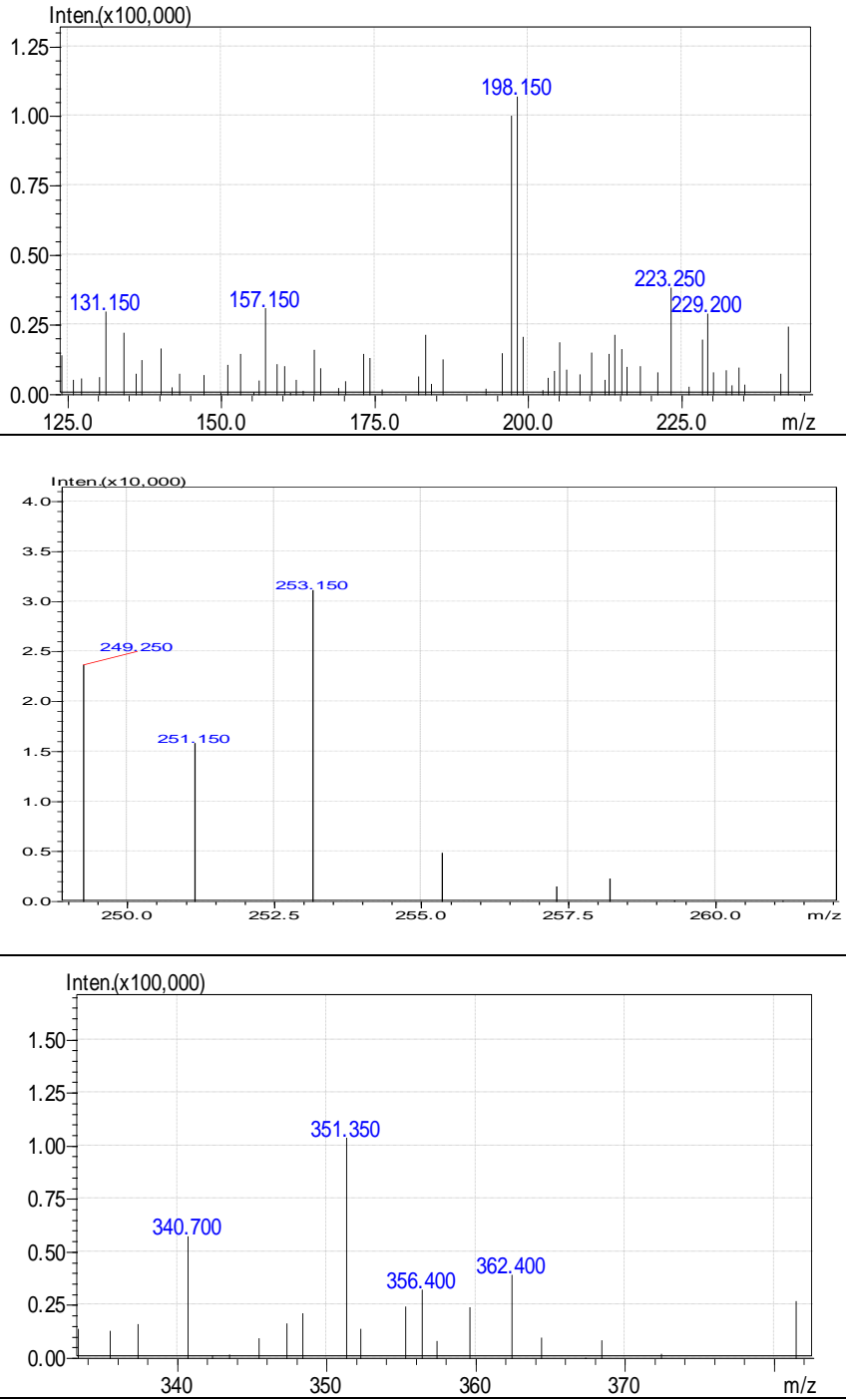

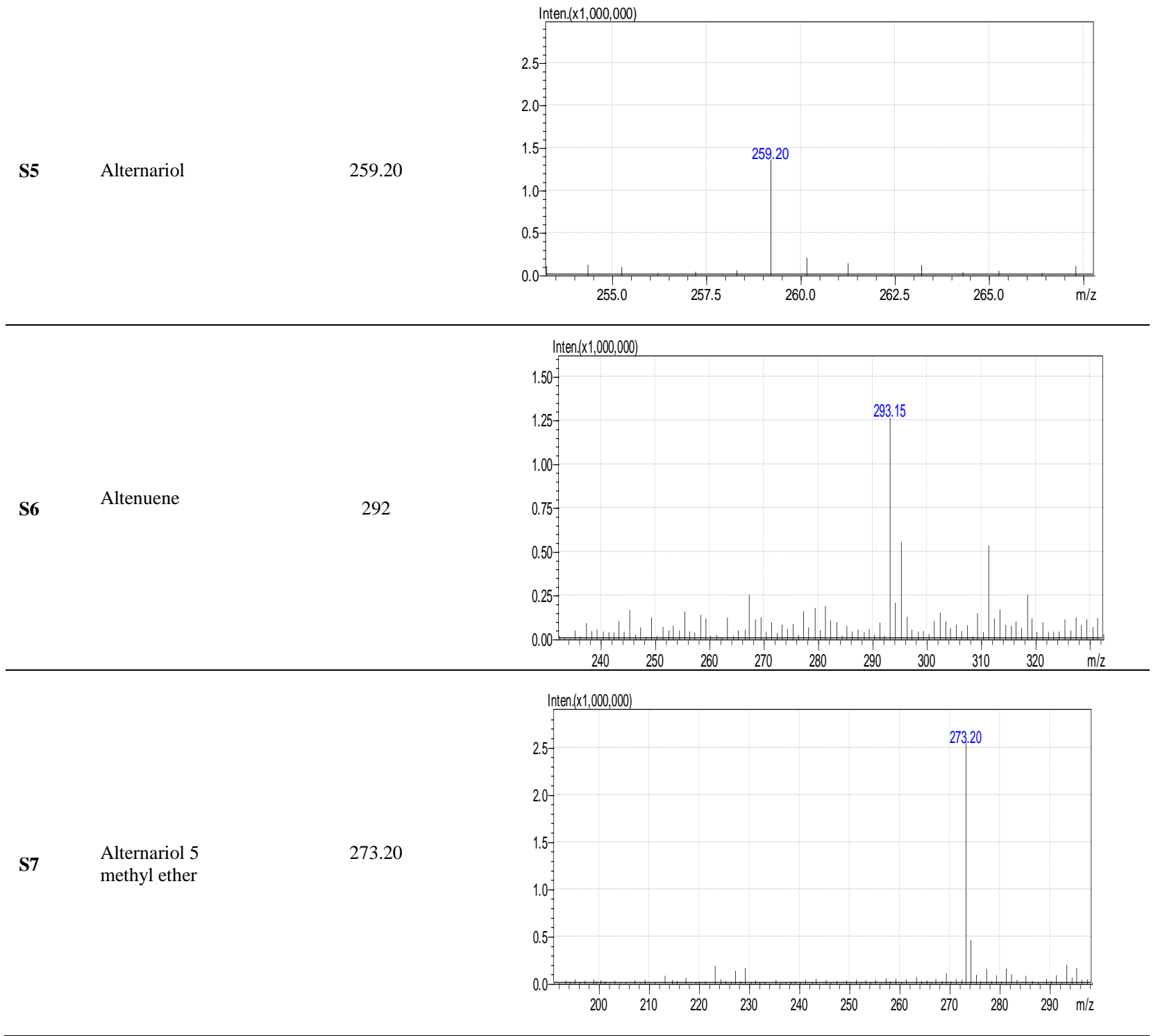

The violet fraction eluted with C: M: 7:3, 11 peaks were observed out of which 1 was identified. Altenuene (Peak No2) was identified at m/z [M+] 293.30 at RT 1.186 and absorbance maxima $250 \mathrm{~nm}$. From NIST Library search, Apigenin-7-O -glocoside, tms- was identified at RT 6.7000 having m/z 864.At RT $8.8000, \mathrm{~m} / \mathrm{z}$ 698 , 2,11-Dibromo-9,18-bis-(2-chloro-phenyl)-5,7,14,16-tetrahydro5,7,8,14,16,17-hexaaza-dibenzo[a,H]cyclotetradecene-6,15-dione was identified Thiabendazole (RT 0.8667, m/z 201), (2)-(1-Acetylazacyclooctacosane)(1acetylazacyclohexacosane)-catenane (RT 6.2333, m/z 842) and L-Tryptophan, N(N-acetyl-L-tyrosyl)-,butyl ester (RT $6.3500, \mathrm{~m} / \mathrm{z} 465$ ) was also identified based on similarity search using NIST Library.

The brown fraction showed 33 peaks of which 1 peak was identified as Alternariol 5 methyl ether at RT $11.497, \mathrm{~m} / \mathrm{z}$ : 274 showing absorbance $274 \mathrm{~nm}$. The other peaks were searched for similarity in NIST Library. From the Library search, Isopthalic acid, butyl 2 -methylcyclohexyl ester (RT 12.1833, m/z 318), 1,6-Dihydroxy-8-methoxy-3-methylanthraquinone, O, O'-bis (trimethylsilyl)(RT 18.4000, m/z 428) and l- Alanine, N-(cyclopentylcarbonyl)-, dodecyl ester (RT 17.7167, m/z 353) were identified.

Mixture analysis of eluted fractions were carried out using proton NMR (500 $\mathrm{MHz}$ Bruker Avance III NMR) to confirm the presence of mass spectrometric based identified compounds viz., Altenuene, Alternarienoic acid AlternariolMonoethyl Ether, Alternariol, Alterperylenol, Stemphyperylenol, Tenuazoic Acid. The proton ppm shifts of standard simulated spectra of each molecules were compared and matched with experimental spectra of each eluted fraction. The characteristic proton shifts of each experimental spectrum falling into particular shift range that represent specific structure also verified. First the experimental spectra of fraction 4, 13 and 16 were processed for binning and deconvulation using topspin software. Further the ppm shifts were adjusted in accordence with the internal standard (tetramethylsilane $0 \mathrm{ppm}$ ). Further the peaks were identified using peak identification algorithm in Topspin and peak lists were generated for each fractions. These peak shifts were matched with the simulated as well as experimental spectra (source: previous literature) of seven compounds which identified through LCMS. the following matches were recorded. 2(H-C-COOR ester), 2.36(H-C-COOH acid), 3.73(RCOO-C-H ester), 3.81(RCOO-C-H ester), 3.83(RCOO-C-H ester). Apart from that, the experimental spectra shows the presence of aromatic rings at the region of 5-6.8 ppm (Ar-H) which confirms the presence of aromatic esters and aromatic acids) The 13th fraction registered matching ppm values of 2.36 (Benzylic $\mathrm{Ar}-\mathrm{C}-\mathrm{H}$ ) 1.62 (Tertiary R3-C-H). Likewise, 16th fraction registered matching shifts of 3.83 (RCOO-C-H ester), 3.81 (RCOO-C-H ester), 2.37 (Benzylic Ar-C-H), 1.62 (Tertiary R3-C-H). These results confirm the presence of the identified compounds which show peculiar structure as depicted above. 

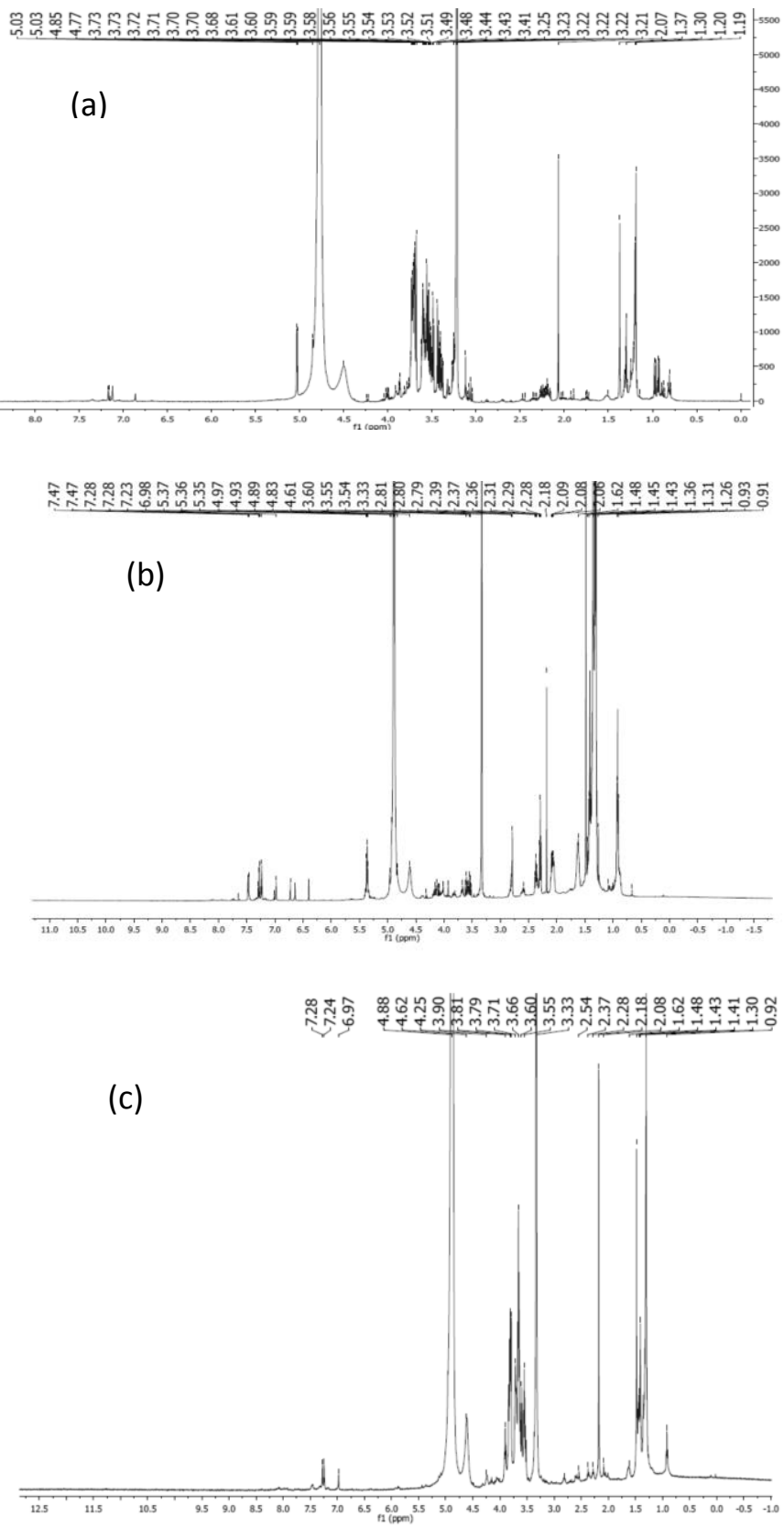

Figure 3 Proton NMR mixture analysis of eluted Fractions 4, 13 and 16 (a) $4^{\text {th }}$ Fraction (b) $13^{\text {th }}$ Fraction (c) $16^{\text {th }}$ fraction.

The predominant classes of fungal secondary metabolites include polyketides, non-ribosomal peptides, terpenes and alkaloids (Keller et al., 2005). Alternaria sp. produce a wide assortment of toxic and non toxic secondary metabolites (Stinson, 1985). A. alternata produces about 60 different metabolites (Saha $\boldsymbol{e}$ al., 2012). Isolation of secondary metabolites like Alteranariol, Altenuene, Alternarienoic acid and Alternariol 5 methyl ether have been reported from ethanolic extracts of Alternaria cultures grown in Rice medium (Kjer, 2009) whereas production of Alternariol is also reported in liquid cultures of Alternaria grown in liquid Wickerham medium in a study (Hassan, 2007). The utilization of Sugarcane bagasse (SB), Corn Bran (CB), Wheat Bran (WB), Fenugreek Straw (FS) and solid medium Cooked Rice (CR) without any supplemental addition by Alternaria alternata and reported SB as productive media for the production of secondary metabolites like Alternariol, Alternariol methyl ether and Tenuzonic acid has also been studied (Ashour et al., 2011). Secondary metabolites from microbes can be utilized for industrial applications and leather dyeing (Velmurugan et al., 2010). The application of fungal pigments in dyeing of cotton, silk and wool have been reported in several studies (Santis et al., 2005; Nagia and El-Mohamedy, 2007; Perumal et al., 2009). Alternaria metabolites exhibit a variety of biological activities such as phytotoxic, cytotoxic, and antimicrobial properties, which have drawn the attention of many chemists, pharmacologists, and plant pathologists in research programs as well as in application studies (Brase $\boldsymbol{e}$ t al., 2009; Tsuge $\boldsymbol{e}$ t al., 2013). Brown pigments from A. alternata expressed good to very good fastness properties to washing, perspiration and light when dyed on wool (Atalla et al., 2011). Olive colour pigments from $A$. alternata dyed on wool shows 4-5 on grey scale rating meaning less staining and excellent wash fastness. The dyes were also tested for toxicity to human skin and have been found to be safe (Sharma et al., 2012). Microbia preparation of herbicide or bio-herbicide can control the growth of weeds. The first evidence that confirmed the herbicidal potential of tenuazonic acid against control of Lantana Camara produced by submerged fermentation of A. alternata (Sanodiya et al., 2010).

\section{CONCLUSION}

The potent applications of metabolites from Alternaria as antitumor agents, herbicides and antimicrobials as well as other promising bioactivities have led to considerable interest within the pharmaceutical community. It is evident from this study that the culture conditions can be modified to obtain maximum pigment production in $A$. alternata. In the present investigation secondary metabolites like Alternarienonic acid, Tenuazoic acid, Stemphyperylenol and Alterperylenol have been observed in the methanol extract of crude pigment whereas compounds like Alternariol, Altenuene, Alternarienoic acid, Alternario 5 methyl ether were predominantly identified in the fractionations from column chromatography of the crude pigment. The Alternaria sp. could be the rich sources of biologically active compounds that are indispensable for medicina and agricultural applications as they produce over sixty different metabolites. However there is very limited information on the utilization of pigments from $A$ .alternata. Also, the interrelationship of factors such as nutrition, $\mathrm{pH}$, and temperature, light exposure in bio regulation and production of secondary metabolites in the micro fungus A.alternata is not much understood. Hence further comprehensive study factors influencing growth, bio-synthesis, isolation and characterization of more secondary metabolites from A. alternata is inevitable and imperative to obtain and elucidate a wide range of secondary metabolites for for promotion of diversified application of these fungal dyes in agriculture, medicine and other industries.

Acknowledgments: We thank Dr. Soumya Swaminathan, Director, Nationa Institute for Research in Tuberculosis, Chetput, Chennai-31 for providing LCMS infrastructure. We thank Dr. E. Murugan, Department of Physical Chemistry, School of Chemical Sciences, University of Madras, Guindy, Chennai-25 for his valuable inputs to conduct the Chromatographic studies. We are grateful to the kind support extended by Dr. V.Sivaram for his scholastic guidance in conducting the mass spectrometry experiments and interpretion of LCMS, FTIR and NMR spectra. We acknowledge Dr. A. Kiran Kumar, and Miss. V. Sudha for technical assistance throughout this work.

\section{REFERENCES}

AITTOMAKI, R., COLLIANDER, H., KOTIRANTA, H. 2000. Varia Luonnosta, 3rd Ed. Heilsinki: Tammi, p. 104

ASHOUR, M., YEHIA, H.M., PROKSCH, P. 2011. Utilization of Agroindustrial by-products for production of bioactive natural products from endophytic fungi. Journal of Natural Products, 4, 108-114.

ATALLA, M.M., EL-KHRISY, E.A.M., YOUSSEF, Y.A., MOHAMED, A. A. 2011. Production of textile reddish brown dyes by fungi. Malaysian Journal of Microbiology, 7, 33-40

BILLS, G. F. 1995. Analyses of micro fungal diversity from a user's perspective. Can. J. Bot, 73(1), 33-41. http://dx.doi.org/10.1139/b95-222

BRASE, S., ENCINAS, A., KECK, J., NISING, C. F. 2009. Chemistry and biology of mycotoxins and related fungal metabolites. Chem. Rev., 109, 39033990. http://dx.doi.org/10.1021/cr050001f

CHANDRASEKARENTHIRAN， S. 2010. "Production, characterization of pigment from selected basidiomycetes - Pycnoporus sanguineus L. Ex. Fries and Coriolus versicolor (L.) Quelet. and application of pigment in textile dyeing" Academic Dissertation, University of Madras, Chennai. India

HASIJA, S.K. 1970. Physiological studies of Alternaria citri and A.tenuis. Mycologia, 62, 289-295. http://dx.doi.org/10.2307/3757587

HASSAN, E. H. A. A. 2007. Novel Natural Products from Endophytic Fungi of Egyptian Medicinal Plants - Chemical and Biological Characterization. Academic Dissertation, Heinrich Heine University Dusseldorf. Germany.

KELLER, N. P., TURNER, G., BENNETT, J. W. 2005. Fungal Secondary Metabolism from Biochemistry to Genomics. Microbiology, 3, 937-947. http://dx.doi.org/10.1038/nrmicro1286

KIM J. K., PARK, S. M., LEE, S. J. 1995. Novel antimutagenic pigment produced by Bacillus licheniformis SSA3. J. Microbiol. Biotechnol., 5, 48-50

KIM, C. H., KIM, S. W., HONG S. I. 1998a. Production of red pigment by Serratia sp. KH-95 and its cultural properties. Kor. J. Biotechnol. Bioeng., 13, 431-437

KIM, C. H., KIM, S. H., HONG, S. I. 1998b. Isolation and characteristics of prodigiosin like red pigment produced by Serratia sp. KH-95. Kor. J. Appl. Microbiol. Biotechnol., 26, 283-289.

KJER, J. 2009. New Natural Products from Endophytic Fungi from Mangrove Plants - Structure Elucidation and Biological Screening. Academic Dissertation, Heinrich Heine University Dusseldorf. Germany. 
LARSEN, T.O., SMEDSGAARD, J., NIELSEN, K. F., HANSEN, M. E, FRISVAD, J. C. 2005. Phenotypic taxonomy and metabolite profiling in microbial drug discovery. Nat. Prod. $R$, 22(6), 672-695. doi http://dx.doi.org/10.1039/b404943h

LAURO, G. J. 1991. A primer on natural colours. Cereal Foods World, 36, 949953

MASAHIRO, K. O., MINE, K., TAYA, M., TONE, S., ICHI, T. 1994 Production and release of anthraquinone pigments by hairy roots of madder (Rubia tinctorum L.) under improved culture conditions. J. Ferment. Bioeng., 77, 103-106. http://dx.doi.org/10.1016/0922-338x(94)90219-4

MISAGHI, I. J., GROGAN, R. G., DUNIWAY, J. M., KIMBLE, K. A. 1977. Influence of environment and culture media on spore morphology of Alternaria alternata. Phytopathology, 68, 29-34. http://dx.doi.org/10.1094/phyto-68-29

NAGIA, F. A., EL-MOHAMEDY, R. S. R. 2007. Dyeing of wool with natural anthraquinone dyes from Fusarium oxysporum. Dyes and Pigments, 75, 550-555. http://dx.doi.org/10.1016/j.dyepig.2006.07.002

OZCELIK, S., OZCELIK, N. 1990. Interacting effects of time, temperature, $\mathrm{pH}$ and simple sugars on biomass and toxic metabolite production by three $\begin{array}{llll}\text { Alternaria } & \text { sp. } & \text { Mycopathologia, } & 109,171-175\end{array}$ http://dx.doi.org/10.1007/bf00436806

PERUMAL, K., STANLEY ABRAHAM, L.,VATSALA, T. M. 2004. Isolation, extraction and dyeing performance of fungal pigment from Ganoderma applanatum, Coriolus versicolor and Amanita muscaria. J. Mycol. Pl. Pathol. 34, 690-691

PERUMAL, K., STALIN, V., CHANDRASEKARENTHIRAN, S., SUMATHI, E., SARAVANAKUMAR, A. 2009. Extraction and characterization of pigmen from Sclerotinia sp. and its use in dyeing cotton. Text. Res. J, 79, $1178-1187$. http://dx.doi.org/10.1177/0040517508087680

PIMENTEL, M. R., MOLINA, G., DIONISIO, A. P., JUNIOR, M. R. M., PASTORE, G. M. 2011. The use of endophytes to obtain bioactive compounds and their application in biotransformation process. Biotechnology Research International, 1, 11. http://dx.doi.org/10.4061/2011/576286

RAISTRICK, H., STICKINGS, C. E., THOMAS, R. 1953. Studies in the biochemistry of micro organisms. 90. Alternariol and alternariol monomethyl ether, metabolic products of Alternaria tenuis. Biochem. J, 55, 421-433

RAMJEGATHESH, R. A., EBENEZAR, E. G. 2012. Morphological and physiological characters of Alternaria alternata causing leaf blight disease of onion. Intl. J. Plant Pathol.., 3, 34-44. http://dx.doi.org/10.3923/ijpp.2012.34.44 SAHA, D., FETZNER, R., BURKHARDT, B., PODLECH, J., METZLER, M., DANG, H. A, LAWRENCE, C., FISCHER, R. 2012. Identification of a Polyketide Synthase Required for Alternariol (AOH) and Alternariol-9- Methyl Ether (AME) Formation in Alternaria alternata. PLoS ONE, 7, 7: e40564. http://dx.doi.org/10.1371/journal.pone.0040564

SANODIYA, B. S., THAKUR, G. S., BAGHEL, R. K., PANDEY, A. K., PRASAD, G. K. S., BISEN, P. S. 2010. Isolation and Characterization of Tenuazonic Acid produced by Alternaria Alternata, A Potential Bioherbicidal Agent for Control of Lantana Camara. Journal of Plant Protection Research, 50 2. http://dx.doi.org/10.2478/v10045-010-0023-3

SANTIS, D. D., MORESI, M., GALLO, A.M., PETRUCCIOLI, M. 2005 Assessment of the dyeing properties of pigments from Monascus purpureus. $J$. Chem. Technol. Biotechnol, 80, 1072 - 1079. http://dx.doi.org/10.1002/jctb.1285 SHABANA, M., ELWAKIL, M. A., CHARUDATTAN, R. 2001. Effect of Nutrition and Physical Factors on Mycelial Growth and Production of Pigments and Nonchromatic UV-absorbing Compounds of Alternaria eichhorniae. Journal of Phytopathology, 149, 21-27. http://dx.doi.org/10.1046/j.14390434.2001.00564.x

SHARMA, D., GUPTA, C., AGGARWAL, S., NAGPAL, N. 2012. Pigment extraction from fungus for textile dyeing. Indian Journal of Fiber and Textile Research, 37, 68-73.

STINSON, E. E. 1985. Mycotoxins-Their biosynthesis in Alternaria. Journal of Food Protection, 48

STROBEL, G. A. 2002. Microbial gifts from rain forests. Can J. Plant Pathol, 24 (1), 14-20. http://dx.doi.org/10.1080/07060660109506965

SUMATHI, E. 2008. "Cultivation, extraction of pigment from basidiomata of Ganoderma lucidum (Fr.) P. Karst and its dyeing performance with selected textile yarns" Academic Dissertation, University of Madras, Chennai. India TSUGE, T., HARIMOTO, Y., AKIMITSU, K., OHTANI, K., KODAMA, M., AKAGI, Y., EGUSA, M., YAMAMOTO, M., OTANI, H. 2013. Host-selective toxins produced by the plant pathogenic fungus Alternaria alternata. FEMS Microbiol. Rev. 37, 44-66. http://dx.doi.org/10.1111/j.1574-6976.2012.00350.x VELMURUGAN, P., KAMALA-KANNAN, S., BALACHANDAR, V., LAKSHMANAPERUMALSAMY, P., CHAE JC, JONG-CHAN., OH, BT 2010. Natural pigment extraction from five filamentous fungi for industrial applications and dyeing of leather. Carbohydrate Polymers, 79, 262-268. http://dx.doi.org/10.1016/j.carbpol.2009.07.058

ZHANG, H. W., SONG, Y. C., TAN, R. X. 2006. Biology and chemistry of endophytes. Nat. Prod. R, 23(5), 753-77. http://dx.doi.org/10.1039/b609472b 